\title{
Determinants of Gender-based Violence Among Girls and Young Women Aged 11-24 Years Seeking Care at a Rural Hospital in Zimbabwe: A Case- Control Study
}

\section{Elizabeth Chipanga}

Africa University Faculty of Health Sciences

Paddington Tinashe Mundagowa ( $\sim$ mundagowap@africau.edu )

Africa University Faculty of Health Sciences https://orcid.org/0000-0002-7788-4874

Violet Chikanya

Africa University Faculty of Health Sciences

\section{Research}

Keywords: Gender-based violence, Religion, Culture, Polygamy, Alcohol abuse, Murambinda

Posted Date: April 6th, 2021

DOl: https://doi.org/10.21203/rs.3.rs-379352/v1

License: (c) (1) This work is licensed under a Creative Commons Attribution 4.0 International License.

Read Full License 


\section{Abstract}

Background: Physical and sexual violence against women and girls has become a widespread public health challenge associated with negative physical and psychological consequences not only to the victim but to society at large. Gender-based violence (GBV) can result in unwanted pregnancies, unsafe abortions, anxiety, stress, depression, and sexually transmitted infections. The problem is more prevalent in low-income settings like Zimbabwe and this study aimed to investigate the determinants of GBV among young women and girls aged between 11-24 years, seeking healthcare services at a rural hospital in Zimbabwe.

Methods: A 1:1 unmatched case-control study was conducted at a rural hospital in Buhera District, Zimbabwe. A total of 104 cases and 104 controls were recruited using purposive and systematic random sampling methods, respectively. The data was collected using a pretested interviewer-administered questionnaire and data were analyzed using Epi Info statistical package. Bivariate analysis and multivariate logistic regression at $95 \%$ confidence interval and statistical significance were set at $p$ value $<0.05$.

Results: The pooled mean age of participants was $17.6 \pm 3.8$ years and $89.4 \%$ of the cases had no familial relations with perpetrators. Bivariate analysis revealed that young age ( $\leq 19$ years), apostolic religion, having no formal education, not married, living in a polygamous family, and having $>3$ siblings were associated with GBV. Cases were more likely to report to a health center and were less likely to confide in someone. The most prevalent causes of GBV were religious and cultural beliefs, forced marriages, and alcohol abuse within a family. After multivariate analysis, young age [Adjusted odds ratio (AOR): 4.8; 95\% Confidence interval (CI):1.3-17.2], polygamy [AOR: 13.8(3.6-53.1)], alcohol abuse in the family [AOR: 4.1(1.3-13.3)] were associated with GBV, while confiding in someone was protective [AOR: 0.05 (0.01$0.2)]$.

Conclusion: Community religious and cultural beliefs and family structure are major areas to consider when intervening against violence against women. To eradicate GBV, there is a need for collaborative multi-sectoral interventions aimed at sensitizing the community on gender equality and the use of peaceful conflict resolution methods. Education on GBV should integrate children of school-going age, faith-based organizations, and community members in crafting sustainable interventions.

\section{Background}

Globally, about 35\% of women have experienced either physical and/or sexual violence by an intimate partner or non-intimate partner violence in their lifetime [1]. Violence against women starts at an early age, with $25 \%$ aged between 15-24-year-old having experienced intimate partner violence by the time they turn twenty-five [2]. Approximately 641 million women become victims of intimate partner violence while six percent of women report sexual assault by someone who is not their partner [2]. Until recently, violence perpetrated against women was primarily treated as a legal and social problem, and in some cases as a 
private matter, rather than being perceived as a public health problem affecting the physical and mental health of millions of women and girls [3].

The United Nations (UN) defines gender-based violence (GBV) as 'any act of gender-based violence that results in, or is likely to result in, physical, sexual, or mental harm or suffering to women, including threats of such acts, coercion or arbitrary deprivation of liberty, whether occurring in public or in private life.' [4]. Gender-based violence is caused by multi-dimensional factors that can be classified into socioeconomic, cultural, religious, and political factors. These can be in the form of physical, sexual, psychological harm including threats, forced virginity testing, or female genital mutilation [5]. While GBV can affect both men and women, the majority of reported GBV cases are women and children [6]. Furthermore, GBV cases are more prevalent in developing countries [6,7]. Literature has shown that GBV was directly or indirectly associated with rural residence, age, number of children, educational status, alcohol abuse, marital conflict, antisocial personality disorder, and witnessing family violence as a child [8-10]

The GBV epidemic is vastly under-reported due to a plethora of barriers such as failure to seek care or report perpetrators by victims because they perceive violence as a common component of life or too petty to report [11]. Previous studies cited shame and stigma [2,11], financial barriers [12], perceived impunity for perpetrators [13], lack of awareness of available services [14,15], accessibility of the services [16], cultural beliefs [17], the threat of separating with children [11], possible retaliation [11], fear of getting the offender incarcerated [18], stereotypical attitudes by the judiciary and law enforcement agencies [19], and lack of trust in health workers [20] as hurdles to reporting cases of GBV.

Gender-based violence hinders the health and daily life activities of women at the individual, community, and national levels. On the other hand, violence against women can cause physical and psychological trauma, injuries, mental disorders, sexually transmitted infections (STIs), gynecological disorders, unwanted pregnancy, as well as increasing the risk of non-communicable diseases [21]. Repeated abuse of women and girls subsequently leads to chronic pain, alcohol and drug abuse, physical disability, and depression [22]. All these conditions have a detrimental effect on the socio-economic development of a society [22] and can negatively impact young women's academic capabilities by undermining their chances of pursuing their academic studies. An increased rate of girls dropping out of schools consequently leads to low economic status among women; thus, increasing women's vulnerability to more GBV as they later become economically dependent on their male partners after marriage [23].

Violence against women and girls is on the rise in developing countries [24]. A World Health Organization (WHO) report revealed that the sub-Saharan Africa (SSA) region has the highest lifetime prevalence of intimate partner violence of $37 \%$ [25]. Surveys conducted with 13 to 24 -year-old adolescents and young women in seven African countries, including Zimbabwe, showed sexual violence rates of more than $20 \%$ among girls under 18, in all seven countries [26]. Sexual violence is widespread in SSA with a recent systematic review reporting that two out of five women had reported intimate partner violence in SSA countries [27], a finding that was consistent with an earlier study conducted in low- and middle-income countries [28]. Nevertheless, this could be an underestimation as a result of underreporting associated 
with GBV $[2,29]$. There are laws and legislation put in place to promote reporting of GBV but women are reluctant to do so due to the barriers mentioned above.

Despite the existence of the Domestic Violence Act 14/2006 law in Zimbabwe, sexual and physical violence offenses against women remain a widespread problem in the country [30]. Zimbabwe has a high prevalence of violence against women and girls with 35\% of women aged between 15-49 years have experienced physical violence and $14 \%$ have experienced sexual violence at least once in their lifetime [30]. To the knowledge of the researchers of this study, there is a dearth of local empirical evidence on the factors contributing to GBV in the country. This study sought to i) identify the socio-demographic factors contributing to GBV, ii) assess the perceptions of GBV and iii)determine the family practices associated with GBV among females aged 11-24 years seeking care at Murambinda Mission Hospital, Buhera District, Manicaland Province, Zimbabwe.

\section{Methods}

\section{Study Design}

An unmatched 1:1 case-control study was carried out to determine the factors contributing to GBV among females aged 11-24 years at Murambinda Mission Hospital.

\section{Study setting}

The study was conducted at Murambinda Mission Hospital, which is $170 \mathrm{~km}$ south-west of Zimbabwe's fourth-largest city of Mutare. The 125-bedded hospital is an affiliation of the Roman Catholic Church and was established in 1968. A total of 27 satellite clinics fall into the Murambinda Mission Hospital catchment area and in 2016, there were 6,170 in-patient admissions, 47,222 out-patient attendances, 1524 babies delivered, and 248 major operations done [31]. The hospital had a staff compliment of four medical doctors, 37 trained nurses, 18 nurse aides, 17 general hands, as well as ancillary and administrative staff. The hospital serves the surrounding rural population of approximately 300,000 people. Data were collected at the Out-patient Department (OPD) which serves an average of 170 patients per day. Besides, the OPD also hosts a One-Stop-Center (victim-friendly unit) for GBV survivors which provides comprehensive psycho-social support, medical examination, confidential voluntary testing and counseling, post-exposure treatment, and follow-up support by a team of trained healthcare workers, police officers, and victim advocates.

\section{Study population}

The study population was made up of female GBV survivors aged 11-24 years seeking healthcare services at Murambinda Mission Hospital. A case was a girl or young woman aged 11-24 years who sought GBV services at the One-Stop-Center of the hospital OPD and resided within Buhera District. A control was a girl or young woman aged 11-24 years who sought services at the hospital OPD presenting with other health complaints which were not GBV-related and lived within Buhera District. 


\section{Sample size and sampling procedure}

Using a 1:1 unmatched case -control study, the sample size was calculated using Epi Info ${ }^{\mathrm{TM}}$ 7.2.1.0 (CDC) Stat-Cal Function at $95 \%$ confidence interval and $80 \%$ power. Assuming alcohol abuse was a significant risk factor for GBV with an Odds Ratio of 2.25 and $30.1 \%$ of the controls exposed [32]. A minimum sample size of 102 cases and 102 controls was calculated giving a total sample size of 204. GBV is a rare complaint; thus, the ideal sampling method for selecting cases was using the purposive sampling method. The systematic random sampling method was used to select controls attended at the hospital OPD using a sampling factor of 3 .

\section{Data collection and analysis}

Pretested, structured, and interviewer-administered questionnaires were used to collect data from the study participants while an unstructured questionnaire was used for key informants whose input was used for data triangulation. The key informants were the Nurse-in-Charge of the OPD, two nurses working in the One-Stop-Centre Clinic, a police officer from the Victim-Friendly Unit, and the District Medical Officer. The study participant questionnaire was translated to a local language Shona by two linguistic experts from Africa University before the two versions underwent validation by two psychotherapists. The data collection tools were pretested at Hauna District Hospital using 21 cases and 21 controls who met the inclusion criteria. Hauna District Hospital is also a rural hospital in the same province as Murambinda Mission Hospital.

The researchers sought consent from the potential participants after they had received all the necessary health services and the doctor had certified that they were stable and fit for interview. The interviews were conducted in a private room and the hospital primary counselors were on alert in case a participant needed further counseling services. The researcher continued to visit the hospital OPD until the calculated minimum sample size of cases and controls was satisfied. Data were collected by EC during the period January 2018 to June 2018. To prevent missing data, the researchers double-checked the answered questionnaire soon after the interview before the participant had left the interview room.

Data from the paper-based questionnaires were entered into Microsoft Excel where it was cleaned before it was imported into Epi Info ${ }^{\text {TM }}$ version 7.2.1.0 (CDC) statistical package for analysis. Statistical analysis included frequencies and means of the socio-demographic characteristics. Bivariate analysis was done to identify the association between the dependent variable (GBV) with the independent variables. The variables that were found to be statistically significant at $p<0.05$ during bivariate analysis were entered into a logistic regression model to control for confounding.

\section{Ethical considerations}

Permission to carry out the study was sought from the Ministry of Health and Child Care through the office of the Provincial Medical Director and the District Medical Officer while ethical clearance was obtained from Africa University Research Ethics Committee (Approval Number: AU313/18). Written 
informed consent was obtained from all study participants and for the minors under the age of 18 , written consent was obtained from the parent or guardian after the participant had verbally assented. Girls under the age of 18 years were interviewed in the presence of their parent/s or guardian/s. Participants were assured of confidentiality and numerical codes were used to identify respondents instead of writing their real names.

\section{Results}

A total of 104 cases and 104 controls were interviewed and the response rate for cases was $92 \%$ while that of controls was $95 \%$. The pooled mean age was $17.6 \pm 3.8$ years (Cases: $15.3 \pm 3.1$ and Controls: $19.9 \pm 3.0$ years) while the pooled mean number of siblings of participants was $5.8 \pm 2.4$ (Cases: $6.5 \pm 2.1$ and controls: $4.9 \pm 2.5)$. While $62.5 \%(n=65)$ of the cases had a history of GBV, only two of the cases were physically challenged, and approximately $89.4 \%(n=93)$ of the cases had no familial relationships with the perpetrators. When given an option of where to report to following a GBV incident, the majority of participants would report to a health facility ( $89 \%$ of controls and $97 \%$ of controls) and not the police. Table 1 shows the socio-demographic characteristics of the study participants.

Table 1. Socio-demographic characteristics of participants $(\mathrm{N}=208)$ 


\begin{tabular}{|c|c|c|c|c|c|}
\hline Variable & Characteristics & $\begin{array}{l}\text { Cases } \\
(n=104)\end{array}$ & $\begin{array}{l}\text { Controls } \\
(n=104)\end{array}$ & $\begin{array}{l}\text { Odds ratio } \\
(95 \% \mathrm{Cl})\end{array}$ & $\begin{array}{l}\mathrm{p}- \\
\text { value }\end{array}$ \\
\hline \multirow[t]{2}{*}{ Age (Completed years) } & $\leq 19$ & 94 & 45 & $\begin{array}{l}12.3(5.8- \\
27.3)\end{array}$ & $0.00 *$ \\
\hline & $>19$ & 10 & 59 & & \\
\hline \multirow[t]{2}{*}{ Religion } & Apostolic & 90 & 64 & $4.0(2.0-8.0)$ & $0.00 *$ \\
\hline & Other & 14 & 40 & & \\
\hline \multirow[t]{2}{*}{ Level of formal education } & None & 34 & 9 & $5.1(2.3-11.3)$ & $0.00 *$ \\
\hline & Primary/secondary & 70 & 95 & & \\
\hline \multirow[t]{2}{*}{ Occupation } & Unemployed & 101 & 84 & $8.0(2.3-27.9)$ & $\begin{array}{l}0.00 * \\
(\mathrm{~F})\end{array}$ \\
\hline & Employed & 3 & 20 & & \\
\hline \multirow[t]{2}{*}{ Marital status } & Not Married & 91 & 29 & $\begin{array}{l}18.1(8.8- \\
37.3)\end{array}$ & $0.00 *$ \\
\hline & Married & 13 & 75 & & \\
\hline \multirow{2}{*}{$\begin{array}{l}\text { Polygamy in } \\
\text { family/marriage }\end{array}$} & Yes & 56 & 12 & $8.9(4.9-18.3)$ & $0.00 *$ \\
\hline & No & 48 & 92 & & \\
\hline \multirow[t]{2}{*}{ Stays with } & Parent/relative/other & 91 & 32 & 15.8(7.7-32.2) & $0.00 *$ \\
\hline & Partner & 13 & 72 & & \\
\hline \multirow[t]{2}{*}{ Number of siblings } & $>3$ & 96 & 74 & $4.9(2.1-11.2)$ & $0.00 *$ \\
\hline & $\leq 3$ & 8 & 30 & & \\
\hline
\end{tabular}

\section{Perceptions of GBV among study participants}

Study participants were asked for their perceptions on action to be taken after the abuse incident plus where and when GBV occurred in Murambinda. Table 2 shows the participant's responses to questions assessing their perceptions on GBV aggregated according to case status.

Table 2. Perceptions of participants on GBV 


\begin{tabular}{|c|c|c|c|c|c|}
\hline Question & Response & $\begin{array}{l}\text { Cases } \\
(n=104)\end{array}$ & $\begin{array}{l}\text { Controls } \\
(n=104)\end{array}$ & $\begin{array}{l}\text { Odds } \\
\text { Ratio } \\
(95 \% \mathrm{Cl})\end{array}$ & $\begin{array}{l}\mathrm{p}- \\
\text { value }\end{array}$ \\
\hline \multirow{3}{*}{$\begin{array}{l}\text { What should one do soon after } \\
\text { being abused? }\end{array}$} & \multirow{2}{*}{$\begin{array}{l}\text { Nothing/don't } \\
\text { know }\end{array}$} & \multirow[t]{2}{*}{64} & \multirow[t]{2}{*}{46} & 2.0 & \multirow[t]{2}{*}{$0.01 *$} \\
\hline & & & & $(1.2-3.5)$ & \\
\hline & $\begin{array}{l}\text { Report to } \\
\text { police/hospital }\end{array}$ & 40 & 58 & & \\
\hline \multirow{3}{*}{$\begin{array}{l}\text { Where can one get support after } \\
\text { abuse? }\end{array}$} & Family & 36 & 28 & 1.4 & 0.2 \\
\hline & & & & $(0.8-3.5)$ & \\
\hline & Other ${ }^{\#}$ & 68 & 76 & & \\
\hline \multirow[t]{2}{*}{$\begin{array}{l}\text { Should one confide in someone after } \\
\text { abuse? }\end{array}$} & Yes & 28 & 87 & $\begin{array}{l}0.07 \\
(0.04- \\
0.1)\end{array}$ & $0.00 *$ \\
\hline & No & 76 & 17 & & \\
\hline \multirow{3}{*}{$\begin{array}{l}\text { How long should one take to visit a } \\
\text { hospital after abuse? }\end{array}$} & $>3$ days & 55 & 22 & 4.2 & $0.00 *$ \\
\hline & & & & $(2.3-7.8)$ & \\
\hline & $\leq 3$ days & 48 & 81 & & \\
\hline \multirow{3}{*}{$\begin{array}{l}\text { What time of the day does GBV } \\
\text { usually occur? }\end{array}$} & Night & 44 & 23 & 2.6 & $0.00 *$ \\
\hline & & & & $(1.4-4.7)$ & \\
\hline & Day & 60 & 81 & & \\
\hline \multirow[t]{3}{*}{ Where does GBV usually occur? } & \multirow{2}{*}{$\begin{array}{l}\text { Private or } \\
\text { secluded places }\end{array}$} & \multirow[t]{2}{*}{81} & \multirow[t]{2}{*}{94} & 0.4 & 0.01 * \\
\hline & & & & $(0.2-0.8)$ & \\
\hline & Other ${ }^{9}$ & 23 & 10 & & \\
\hline
\end{tabular}

*p-value<0.05: statistically significant result, Other\#: neighbor/friend/police/religious leader/ Social Services Organization, Other': home/school/public places, OR: Odd ratios, Cl: Confidence interval

\section{Practices associated with GBV}

All participants reported that rape was regarded as a form of sexual violence in their families. Sexual touching/kissing and attempted sex were regarded as a form of sexual violence by the families of $16.8 \%$ $(n=35)$ and $12 \%(n=25)$ of the participants, respectively. The most common causes of GBV in the study community were evil spirit cleansing and forced marriages as reported by $87 \%(n=181)$ and $84.1 \%$ $(n=175)$ of the participants, respectively. Most of the study participants cited HIV and STIs $(70.7 \%$, 
$n=147)$, unwanted pregnancy $(66.8 \%, n=139)$, and psycho-social trauma $(36.1 \%, n=75)$ as the common negative impacts of GBV on families. The major reasons for not reporting were protecting religious and family beliefs, and poverty as reported by $71.6 \%(n=149)$ and $65.4 \%(n=136)$ of the respondents, respectively. Table 3 shows family practices associated with GBV. After bivariate analysis, all variables which were statistically significant at $p<0.05$ were imputed for logistic regression analysis, and the findings are displayed in Table 4. Interviews with the key informants also identified the causes of GBV in Buhera District as poverty, patriarchal nature of the communities, and restrictive religious belief. Girls married early with the help of the financial security that comes with having a male intimate partner taking care of their financial needs. The majority of families were affiliated with the apostolic sects whose clandestine and conservative actions made it difficult for the women's rights groups to penetrate the communities. The authoritative leadership of the apostolic sects warned their female members to refrain from GBV-related discussions which were viewed as 'secular'.

Table 3. Family practices relative to GBV

\begin{tabular}{|llllll|}
\hline & Responses & $\begin{array}{l}\text { Cases } \\
(\mathbf{n}=208)\end{array}$ & $\begin{array}{l}\text { Controls } \\
(\mathbf{n}=204)\end{array}$ & OR (95\%Cl) & p-value \\
\hline Family discusses GBV issues & No & 96 & 88 & $2.2(0.9-5.4)$ & 0.08 \\
\cline { 2 - 6 } & Yes & 8 & 16 & & \\
\hline There is alcohol abuse in the family & Yes & 80 & 56 & $2.9(1.6-5.2)$ & $0.00^{*}$ \\
\cline { 2 - 6 } & No & 24 & 48 & & \\
\hline Family allows reporting of GBV & Yes & 95 & 101 & $0.3(0.08-1.2)$ & 0.07 \\
\cline { 2 - 6 } & No & 9 & 3 & & \\
\hline
\end{tabular}

${ }^{*} \mathrm{p}$-value<0.05: statistically significant result, OR: Odd ratios, $\mathrm{Cl}$ : Confidence interval

Table 4. Results of the logistic regression analysis

\begin{tabular}{|llll|}
\hline Variable & AOR $(95 \% \mathrm{Cl})$ & Coefficient & p-value \\
\hline Age ( $\leq 19$ years of age) & $4.8(1.3-17.2)$ & 1.6 & $0.02^{*}$ \\
\hline Living in a polygamous marriage/ family & $13.8(3.6-53.1)$ & 2.6 & $0.00^{*}$ \\
\hline Confiding in someone & $0.05(0.01-0.2)$ & -3.1 & $0.00^{*}$ \\
\hline Alcohol abuse present in the family & $4.1(1.3-13.3)$ & 1.4 & $0.02^{\star}$ \\
\hline
\end{tabular}

${ }^{*} \mathrm{p}$-value<0.05: statistically significant results, AOR: Adjusted odds ratios, Cl: Confidence interval

\section{Discussion}


This study sought to identify the socio-demographic factors contributing to GBV, assess the perceptions of GBV, and determine the family practices associated with GBV among females aged 11-24 years seeking care at Murambinda Mission Hospital, Buhera District, Manicaland Province, Zimbabwe. After controlling for confounding variables, a young age, living in a polygamous family, and alcohol abuse in the family were found to be strong predictors of GBV in the present study. Forced marriages, religious and cultural beliefs were also perceived as causes of GBV while the women and girls preferred to report to the hospital than to the police.

The study findings revealed that the mean age of cases was lower than that of controls and young girls (11-19 years) were nearly five times more likely to be victimized when compared to young women (20 to 24 years of age). Adolescent girls are at a higher risk of becoming GBV victims $[28,33]$ and this can be attributed to limited experience in relationships particularly with male partners who are older than them [34]. In intergenerational relationships, young girls lack the power to make autonomous decisions; hence they are forced into sexual acts which they usually regret later in life. This was also reported in a similar study that found out that for almost half of female childhood (under the age of 18 years) sexual victims, the perpetrators were five or more years older [35].

One of the most common causes of GBV identified by the participants in this study was religion and culture-related evil spirit cleansing. Although there has been a growing upsurge in international efforts to end violence against women, many groups lobbying for women's rights usually withhold their denouncing of GBV when it is associated with the 'culture' or 'religion' of a certain community [36]. These groups tend to play down violence against women and girls as an authentic practice justified for preserving the cultural, religious, and traditional sovereignty of the communities. Legitimizing violence based on culture and religion conversely deprives women and girls of their self-determination rights as well as control of their bodies and sexuality. Since those who employ culture and religion to justify GBV do it because of their interpretation of one 'authentic' view oblivious of alternatives, it is critical to demystify such beliefs by exposing the alternatives to them [36]. Many societies have normalized the attitudes and systems that elevate religious doctrine endorsed by male authorities and these patriarchal structures have also regularized violence in the society [37]. Therefore, to reduce GBV emanating from misguided religious beliefs, religious institutions must improve women's representation in leadership positions while communities should be empowered and resourced to host multi-faith women networks [38]. These networks can be used for interactive communications and discussions on GBV issues among both men and women in the communities. Religious leaders also have to amplify their voices and exercise their influence to communicate a vivid message against GBV.

The researchers also noted that forced marriages were a common source of GBV in this community. Globally, over 1.5 million girls younger than 15 years are married annually [39] and there were an estimated 15.4 million people who were living in forced marriages in 2016, 88\% of these were women and girls [40]. There are a variety of reasons why forced marriages take place, and these include economic incentives, conflict settlement, and preserving family 'honor' by forcing girls or women who have been raped to marry the rapist [41]. Forced marriages emanate from the perspective that girls are property that 
can be exchanged with such views being reinforced by culturally accepted mores and precedents. Education on the importance of gender equality and empowering the girl child can be used to defeat the age-old patriarchal structures.

The major reason why some women in this community did not report perpetrators was that they wanted to protect religious beliefs and poverty forced girls into early marriages. In Zimbabwe, cultural beliefs are girded by the male-dominated influence which seeks to protect the family name, even if that meant sacrificing a family member's dignity. Social norms that are intolerant to extramarital pregnancy while blaming women and girls for becoming pregnant outside marriage diminishes the victim's will to report cases due to self-blame. A study by Perrin et al., (2019), in Somalia and South Sudan, noted the stigma associated with being a member of the family where the emphasis was placed on addressing GBV within the family rather than reporting to authorities [42]. This was done to protect the family name over the safety and wellbeing of the victim. Orienting women and girls on self-preservation can help them understand that violent behavior is wrong and should be denounced at all costs.

Women living in a polygamous family or marriage were more likely to become victims of GBV. The social complexity of polygamous/polygynous marriages exposes the women involved to GBV [43]. Polygyny is very common in sub-Saharan Africa [44] and a recent study noted that the practice is associated with intimate partner violence of a prevalence of $30.7 \%$ [45]. This could be attributed to polygamous families having poor social interaction as a result of co-family rivalries over resources [46]. Although GBV within polygamous families is difficult to tackle, such families must be educated on the importance of peaceful resolution of conflicts and shun violence. The high rates of GBV among polygamous families in Buhera District warrants further qualitative inquiry to establish specific solutions for this specific population.

Participants who lived in families where alcohol was abused were more likely to become victims of GBV. This was also the case in a similar study conducted in Zambia where alcohol drinking behavior increased the odds of GBV by more than double [32]. Alcohol interferes with cognitive and physical functions of the body diminishing self-control, and ultimately leaving the person incapable of negotiating conflicts and confrontations in a non-violent manner [47]. Problematic masculine alcohol intake is associated with increased sexualized behavior [48]. Alcohol abuse also culminates into financial difficulties, infidelity, and childcare problems which can potentially lead to intimate partner violence and child abuse [49]. In Buhera District, traditional alcohol is brewed in the communities where unemployed men go to buy and drink the cheap brew as a way of killing time. As a result, these men may physically or sexually assault their partners or other women as a way of venting their frustrations. Abusing alcohol has also been linked to risky sexual behavior which can result in the exposure of the GBV victims to sexually transmitted infections such as HIV/AIDS.

The study participants viewed contracting HIV and STIs, and unwanted pregnancy as the most devastating consequences of GBV. Research into the high prevalence of HIV among girls and young women in sub-Saharan Africa reported that the risk and vulnerability to HIV among this population are deep-rooted in violence against women [50]. According to the UNESCO Report (2013), the risk of HIV 
among women increases three-fold in women who have experienced GBV when compared to those who have not [50]. Forced sexual intercourse with an HIV-infected individual increases trauma-causing lacerations and abrasions which provide easy entry of STIS/HIV. Although most STIs can be treated, there is no treatment for HIV/AIDS, a disease often stigmatized in many communities. Unwanted pregnancies, particularly as a result of sexual violence, can lead to long-term poor mental health outcomes [51]. Women and girls should know the importance of the prompt visit to the health facility after they have been sexually abused so that they receive post-exposure prophylaxis of HIV as well as legal abortion services.

The majority of participants in this study stated that following a GBV incident, they would report to a hospital or clinic rather than the police. This finding was consistent with other studies which cited that raped women were highly unlikely to report to the police [52]. In Zimbabwe, reporting violence cases to law enforcement authorities may be hampered by persistent socio-economic and political instability which saw women suffering violence and torture at the hands of security forces along with the police departments being perceived as politically infiltrated by individuals in leadership positions $[53,54]$. As a result, citizens may have reservations about reporting when the authorities who are supposed to protect them, persecute them instead. Likewise, literature has also noted how conflict and humanitarian emergencies expose women and girls to the risk of GBV [55,56]. Thus, the health facility becomes an appropriate and convenient reporting place for GBV survivors rather than the police, because the OneStop-Centre establishment provides comprehensive aftercare medical, counseling, legal services, and even the police, under one roof.

Participants believed that it was important to confide in another trusted person after experiencing GBV. Women deride reporting to authorities like police due to the fear of either being blamed or not believed; thus, victims choose a trustworthy confidante, most likely a close friend, who can offer emotional support $[52,57]$. Blaming GBV survivors seeking solace was associated with increased rates of re-victimization over a period of twelve months [57]. Despite the limited effect of the positive confidante reactions, the opposite, which negative reactions such as blame and rejection, can cause psychological harm to survivors [58]. Summarily, sincere responses from friends and trusted others matter deeply.

\section{Limitations}

When interpreting the findings of this study, one should consider the possibility of potential social desirability bias due to the sensitive nature of the topic and self-reporting of participants. Besides, this study may have missed women who were GBV survivors who did not report to the OPD at Murambinda Mission Hospital, consequently, this can have a major bearing on the generalizability of the findings.

\section{Conclusions}

Gender-based violence is an important public health challenge in Buhera District. The religious and cultural beliefs, as well as family structure, are major areas to consider when intervening against violence against women in this population. To eradicate GBV, trained health personnel, religious, and traditional 
leaders could be used as champions to intensify the message of gender equality and the use of conflict resolutions that do not involve violence. Education on GBV should integrate children of school-going age, faith-based organizations, and community members in crafting sustainable interventions. Furthermore, the researchers recommend a qualitative, community-based prospective study that will cover the entire district guided by findings from this study.

\section{Abbreviations}

AIDS Acquired immune-deficiency syndrome

GBV Gender-based violence

HIV Human-immunodeficiency virus

OPD Out-patient department

STI Sexually transmitted infections

SSA Sub-Saharan Africa

UN United Nations

WHO World Health Organizations

\section{Declarations}

\section{Ethics approval and consent to participate}

The protocols were carried out following the Africa University Research Ethics Committee guidelines and regulations. Written informed consent was obtained from all participants of the study. Permission to carry out the study was sought and obtained from the Ministry of Health and Child Care of Zimbabwe through the office of the Provincial Medical Director. Ethical clearance was obtained from Africa University Research Ethics Committee.

\section{Consent for publication}

Not Applicable

\section{Availability of data and materials}

The datasets used and/or analyzed during the current study are available from the corresponding author on reasonable request

\section{Competing interests}


Authors declare that they have no competing interests

\section{Funding}

None

\section{Authors' contributions}

EC came up with the concept, wrote the protocol, and collected the data. PM analyzed the data and wrote the first manuscript draft. VC supervised the study. EC, VC, and PM reviewed the manuscript and made essential adjustments. All authors read and approved the final manuscript.

\section{Acknowledgments}

The authors are grateful to the staff at Murambinda Mission Hospital OPD Department for their cooperation and the study participants whose input was invaluable to the success of this work.

\section{References}

1. World Health Organization. Respect women: preventing violence against women. Sexual and Reproductive Health. 29 May 2019. https://www.who.int/reproductivehealth/topics/violence/respectwomen-framework/en/ Accessed: Dec 19, 2020

2. UN News. Endemic violence against women 'cannot be stopped with a vaccine'-WHO Chief. March 9, 2021. Available at: https://news.un.org/en/story/2021/03/1086812 Accessed: March 18, 2021.

3. Fairburn J. Before \#MeToo: Violence against women social media work. Bystander intervention, and social change. Societies. 2020;10(51).

4. United Nations. Declaration on the elimination of violence against women. New York: UN, 1993.

5. Sanjel S. Gender-based violence: a crucial challenge for public health. Kathmandu Univ Med J. 2015;11(2):179-184.

6. García-Moreno C, Pallitto C. Global and Regional Estimates of Violence against Women: Prevalence and Health Effects of Intimate Partner Violence and Non-Partner Sexual Violence; WHO: Geneva, Switzerland, 2013.

7. Pallitto, CC, Jansen HA, Ellsberg M, Heise L, Watts CH. WHO Multi-country Study on Women's Health and Domestic Violence against Women Study Team. Prevalence of intimate partner violence: Findings from the WHO multi-country study on women's health and domestic violence. Lancet. 2006; 368:1260-1269.

8. Hindin MJ, Adair LS. Who's at risk? Factors associated with intimate partner violence in the Philippines. SocSci Med. 2002;55(8):1385-99.

9. Karamagi CA, Tumwine JK, Tylleskar T, Heggenhougen K. Intimate partner violence against women in eastern Uganda: implications for HIV prevention. BMC Public Health. 2006;6(1):284.

10. Violence against women. March 9, 2021. https://www.who.int/news-room/factsheets/detail/violence-against-women Date accessed: March 17, 2021. 
11. Garcia-Moreno C, Jansen HA, Ellsberg M, et al. WHO Multi-Country Study on Women's Health and Domestic Violence against Women: Initial Results on Prevalence, HealthOutcomes and Women's Responses. Geneva, Switzerland: World Health Organization; 2005.

12. International Center for Research on Women, GBV Prevention Network, MRC South Africa. Strengthening Research and Action on Gender-Based Violence in Africa. Washington, DC: International Center for Research on Women; 2012.

13. Ohambe MCO, Muhigwa JBB, Wa Mamba BM. Women's Bodies as a Battleground: Sexual Violence against Women and Girls During the War in the Democratic Republic of Congo. South Kivu (19962003). Uvira and Bukavu, DemocraticRepublic of Congo: Réseau des Femmes pour unDéveloppementAssociatif, Réseau des Femmes pour laDéfense des Droits et la Paix, International Alert; 2005.

14. Hossain M, Zimmerman C, Kiss L, et al. Violence Against Women and Men in Cote d'Ivoire: A Cluster Randomized Controlled Trial to Assess Impact of the 'Men \& Women in Partnership' Intervention on the Reduction of Violence Against Women and Girls in Rural Cote d'Ivoire-Results From a Community Survey. London, United Kingdom: London School of Hygiene and Tropical Medicine; 2010.

15. Casey SE, Gallagher MC, Rukengeza Makanda B, et al. Care-seeking behavior by survivors of sexual assault in the Democratic Republic of the Congo. Am J Public Health. 2011;101(6):1054-1055.

16. Kishor S, Hindin MJ. Profiling Domestic Violence: A Multi-Country Study. Calverton, MD: Measure DHS and ORC Macro; 2004.

17. Njuki R, Okal J, Warren CE, et al. Exploring the effectiveness of the output-based aid voucher program to increase uptake of gender-based violence recovery services in Kenya: a qualitative evaluation. BMC Public Health. 2012;12(1):426.

18. Dutton MA, Green BL, Kaltman SI, et al. Intimate partner violence, PTSD, and adverse health outcomes. J Interpers Violence. 2006;21(7):955-968.

19. Amnesty International. Colombia: Hidden From Justice, Impunity for Conflict-Related Sexual Violence, a Follow-up Report. London, United Kingdom: Amnesty International; 2012.

20. Rodriguez MA, Quiroga SS, Bauer HM. Breaking the silence: battered women's perspectives on medical care. Arch Fam Med.1996;5(3):153-158.

21. Fulu E. Violence against women and girls. GSDRC Professional Development Reading Pack no. 32. Birmingham: University of Birmingham; 2016.

22. Heise L, Ellsberg M, Gottemoeller M. Ending violence against women. Popul Rep. 999;27(4):1-1.

23. Unsafe Schools: A literature review of school-related gender-based violence in developing countries. 2003.

24. Gage AJ. Women's experience of intimate partner violence in Haiti. Soc Sci Med. 2005;61:343-64.

25. World Health Organization (WHO). Global and regional estimates of violence against women: prevalence and health effects of intimate partner violence and non-partner sexual violence. 2013. https://apps.who.int/iris/bitstream/handle/10665/85239/9789241564625_eng.pdf?sequence=1 
26. Violence against women- Evidence brief. World Health Organization, 2019. Available at: https://www.who.int/reproductivehealth/publications/vaw-evidence-brief/en/ Date accessed: March 18,2021

27. Muluneh MD, Stulz V, Francis L, Agho K. Gender based violence against women in Sub-Saharan Africa: a systematic review and meta-analysis of cross-sectional studies. International Journal of Environmental Research and Public Health. 2020;17(903).

28. Decker MR, Latimore AD, Yasutake S, Haviland M, Ahmed S, Blum RW, Sonenstein F, Astone NM. Gender-based violence against adolescent and young adult women in low- and middle-income countries. J Adolesc Health. 2015 Feb; 56(2):188-96.

29. Palermo T, Bleck J, Peterman A. Tip of the iceberg: reporting and gender-based violence in developing countries. Am J Epidemiol. 2014 Mar 1; 179(5):602-12.

30. Zimbabwe National Statistics Agency (ZIMSTAT). Multiple Indicator Survey 2014. Key Findings. Harare, Zimbabwe. 2014.Friends of Murambinda Hospital, 2016. Available at: https://fmh.org.uk/about-2/

31. Ngonga Z. Factors contributing to physical Gender Based Violence reported at Ndola Central Hospital, Ndola, Zambia: A case control study. Medical Journal of Zambia. 2016;43(3):145-151.

32. Mukaman IJ, Machakanja P, Adjei NK. Trends in prevalence and correlates of intimate partner violence against women in Zimbabwe, 2005-2015. BMC Int Health Hum Rights. 2020;20(2).

33. Akintola O, Ngubane L, Makhaba L. 'I did it for him not me': an exploratory study of factors influencing sexual debut among female university students in Durban, South Africa. J Health Psychol. 2012;17(1):143-153.

34. Beyene AS, Chojenta C, Roba HS, Melka AS, Loxton D. Gender-based violence among female youths in educational institutions of Sub-Saharan Africa: a systematic review and meta-analysis. Systematic Reviews. 2019;8(59).

35. Greiff S. No justice in justifications: Violence against women in the name of culture, religion, and tradition. The Global Campaign to Stop Killing and Stoning Women and Women Living Under Muslim Laws. 2010.

36. Carter J. A call to action: religion, women, violence and power. Simon and Schuster, New York. 2014.

37. The role of religious communities in addressing gender-based violence and HIV. USAID Health Policy Initiative. August 2009.

38. Brown G. Out of wedlock, into school: combating child marriage through education. The Office of Gordon and Sarah Brown, London. 2013.

39. Global estimates of modern slavery: forced labor and forced marriage. 2017.

40. Ertürk, Y. (2007). Intersections between culture and violence against women. http://daccessods.un.org/TMP/3670902.25219727.html. Implementation for the General Assembly Resolution 60/251 of 15 March 2006 Entitled "Human Rights Council". Report of the Special Rapporteur on violence against women, its causes and consequences, Yakin Ert"urk. Human Rights Council. Fourth session. Item 2 of the provisional agenda. Distr. General: A/HRC/4/34. January 17, 2007 
41. Perrin N, March M, Clough A, Desgroppes A, Phanuel, CY, Abdi A, et al. Social norms and beliefs about gender based violence scale: a measure for use with gender based violence prevention programs in lo-resource and humanitarian settings. Conflict and Health. 2019;13:6

42. Jansen N, Agadjnian V. Polygyn and intimate partner violence in Mozambique. Journal of Family Issues. 2019; 41(3):338-358.

43. Amo-Adjei J, Tuoyire DA. Do ethnicity and polygyny contribute to justification of men beating women in Ghana? Women \& Health. 2016;56(1):48-64

44. Ahinkorak BO. Polygyny and intimate partner violence in sub-Saharan Africa: Evidence from crosssectional demographic and health surveys. SSM Population Health. 2021;13:100729.

45. Heath R, Hidrobo M, Roy S. Cash transfers, polygamy, and intimate partner violence: Experimental evidence from Mali. Journal of Development Economics. 2020;143:102410.

46. Interpersonal violence and alcohol. World Health Organization Policy Briefing. 2006.

47. Our Watch, ANROWS, VicHealth. Change the Story:

A Shared Framework for the Primary Prevention of

Violence Against Women and their Children in Australia.

Melbourne (AUST): Our Watch; 2015.

48. Taft A, Wilson I, Laslett A, Kuntsche S. Pathway to responding and preventing alcohol-related violence against women: why gendered approach matters. Australian and New Zealand Journal of Public Health. 2019;43(6):516-518.

49. Addressing the links between gender-based violence and HIV in the Great Lakes region. Regional Workshop $15^{\text {th }}-16^{\text {th }}$ July 2013, Dar-es-Salaam, Tanzania. Division of Gender Equality UNESCO.

50. Decker MR, Peitzmeier S, Olumide A, Acharya R, Ojengbede O, Covarrubias L, Gao E, Cheng Y, DelanyMoretlwe S, Brahmbhatt $\mathrm{H}$. Prevalence and health impact of intimate partner violence and nonpartner sexual violence among female adolescents aged 15-19 years in vulnerable urban environments: a multi-country study. J Adolesc Health. 2014;55(6):S58-67.

51. Ahrens C, Campbell R, Ternier K, Wasco S, Sefl T. Deciding who to tell: Expectations and outcomes of rape survivors' first disclosures. Psychology of Women Quarterly. 2007;31:38-49.

52. Zengenene $M$, Susanti E. Violence against women and girls in Harare, Zimbabwe. Journal of International Women's Studies. 2019;20(9), 83-93.

53. Moyo K. Forbidden Truth: Background to Truth Recovery in Zimbabwe, Challenges, Opportunities and Threats. 2013. Paper presented at the Second International Conference on Transitional Justice in Zimbabwe.

54. Sloand E. Killion C, Gary FA, Dennis B, Glass N, Hassan M, et al. Barriers and facilitators to engaging communities in gender-based violence prevention following a natural disaster. J Health Care Poor Underserved. 2015;26(4):1377-90.

55. Wirtz AL, Pham K, Glass N, Loochkartt S, Kidane T, Cuspoca D, et al. Gender-based violence in conflict and displacement: qualitative findings from displaced women in Colombia. Confl Health. 2014;8:10. 
56. Mason GE, Ullman S, Long SE, Long L, Starzynski L. Social support and risk of sexual assault revictimization. Journal of Community Psychology. 2009; 37(1): 58-72

57. Ullman SE, Karabatsos G, Koss MP. Alcohol and sexual assault in a national sample of college women. Journal of Interpersonal Violence. 1999;14(6):603-625.

\section{Figures}

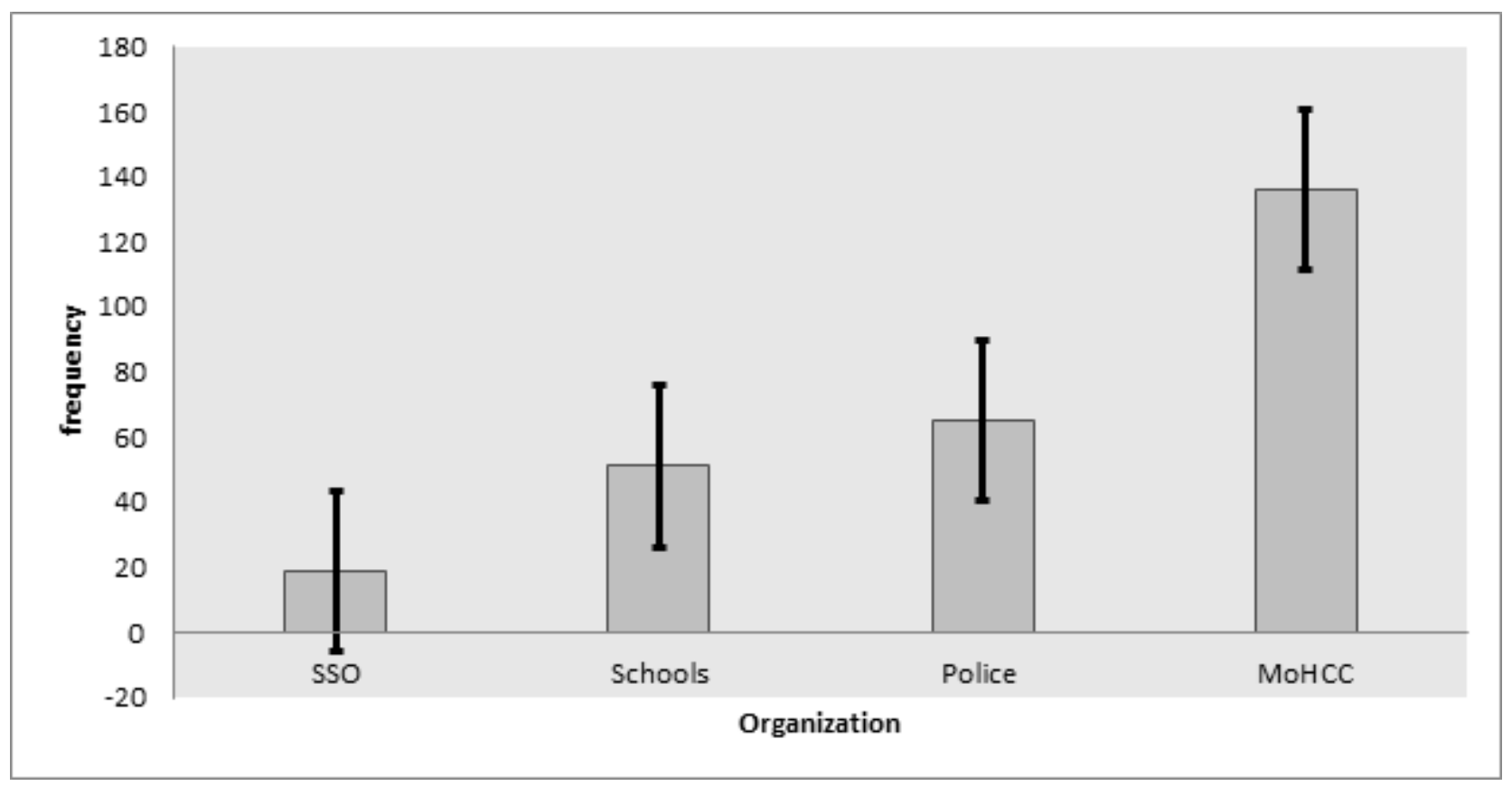

\section{Figure 1}

SSO: Social Services Organization, MoHCC: Ministry of Health and Child Care Sources of health education on GBV in Murambinda District as identified by study participants. 